\title{
Collaborative modelling for active involvement of stakeholders in urban flood risk management
}

\author{
M. Evers ${ }^{1, *}$, A. Jonoski ${ }^{2}$, Č. Maksimovič ${ }^{3}$, L. Lange ${ }^{1, *}$, S. Ochoa Rodriguez ${ }^{3}$, A. Teklesadik ${ }^{2, *}$, J. Cortes Arevalo $^{4, * *}$, \\ A. Almoradie ${ }^{2}$, N. Eduardo Simões ${ }^{3}$, L. Wang ${ }^{3}$, and C. Makropoulos ${ }^{5}$ \\ ${ }^{1}$ University of Wuppertal, Working Group General Geography/Human-Environment Research, Gaußstrasse 20, \\ 42119 Wuppertal, Germany \\ ${ }^{2}$ UNESCO-IHE Delft, Department of Hydroinformatics and Knowledge Management, Westvest 72611 AX Delft, \\ The Netherlands \\ ${ }^{3}$ Imperial College London, Department of Civil and Environmental Engineering, London, SW7 2AZ, UK \\ ${ }^{4}$ CNR-IRPI, National Research Institute for Geohydrological protection, Via Madonna Alta, 126 - 06128 Perugia PG \\ Umbria, Padova, Italy \\ ${ }^{5}$ National Technical University of Athens, School of Civil Engineering, 28 Oktovriou (Patision) 42, 10682 Athens, Greece \\ * formerly at: Leuphana University of Lüneburg, Germany \\ *** formerly at: UNESCO-IHE Delft, The Netherlands
}

Correspondence to: M. Evers (mariele.evers@uni-wuppertal.de)

Received: 22 December 2011 - Revised: 6 July 2012 - Accepted: 19 July 2012 - Published: 12 September 2012

\begin{abstract}
This paper presents an approach to enhance the role of local stakeholders in dealing with urban floods. The concept is based on the DIANE-CM project (Decentralised Integrated Analysis and Enhancement of Awareness through Collaborative Modelling and Management of Flood Risk) of the 2nd ERANET CRUE funding initiative. The main objective of the project was to develop and test an advanced methodology for enhancing the resilience of local communities to flooding. Through collaborative modelling, a social learning process was initiated that enhances the social capacity of the stakeholders due to the interaction process. The other aim of the project was to better understand how data from hazard and vulnerability analyses and improved maps, as well as from the near real-time flood prediction, can be used to initiate a public dialogue (i.e. collaborative mapping and planning activities) in order to carry out more informed and shared decision-making processes and to enhance flood risk awareness. The concept of collaborative modelling was applied in two case studies: (1) the Cranbrook catchment in the UK, with focus on pluvial flooding; and (2) the Alster catchment in Germany, with focus on fluvial flooding. As a result of the interactive and social learning process, supported by sociotechnical instruments, an understanding of flood risk was developed amongst the stakeholders and
\end{abstract}

alternatives for flood risk management for the respective case study area were jointly developed and ranked as a basis for further planning and management.

\section{Introduction}

Currently, we are facing a paradigm shift in Europe in dealing with flood issues from flood protection towards flood risk management (FRM). One reason for this shift is the increase of flood events and related flood damages during the last decades (IPCC, 2007; Stern, 2006; Schwarz et al., 2008; EEA, 2007, 2009; MunichRe, 2006). Another reason is the ongoing discourse on governance structures and processes and the discussion on changing the approaches to management of natural hazards.

One significant consequence of this paradigm shift is the adoption of the Flood Directive (2007/60/EC) in 2007 by the European Union, which is demanding flood risk assessment, flood risk management plans and the involvement of interested parties in the implementation process of the Flood Directive as a new approach to dealing with FRM. Similarly to other areas of environmental management, like river basin management and urban development projects, FRM 
has identified stakeholder involvement and participatory approaches as crucial for its successful and sustainable implementation (Hisschemöller et al., 2011; Abbott, 2007; Steinführer et al., 2008; Pasche et al., 2009; Watson et al., 2009; Pitt, 2008; Dawson et al., 2011).

The context for the research work presented in the current paper is provided by several key findings from previous studies related to stakeholder involvement in FRM, which are presented as follows:

1. FRM must be accomplished locally and needs to be developed in consultation with local stakeholders. Change of paradigm implies a shift to individualisation of risk and social vulnerability; therefore, shifting from top down to participatory governance approach is essential (Steinführer et al., 2008).

2. Regarding the use of non-structural measures for reducing flood risk in small urban catchments, the key factor for success is capacity building especially of local stakeholders (Pasche et al., 2008).

3. An acknowledgement of the key role of local champions - pro-active individuals that involve and support diverse members of a given community in FRM processes. It is necessary to assist the local communities to make "informed decisions" because there are numerous biases and cognitive shortcuts that can be invoked by individuals as they try to qualify the costs and benefits for themselves (Watson et al., 2008).

4. Local authorities should take the lead in FRM and surface water management in small urban catchments (Pitt, 2008).

5. A portfolio of land use and non-structural measures should be developed, and realistic scenarios are needed to explore the feedbacks across sectors (Dawson et al., 2011).

Based upon these findings, we developed a collaborative modelling (CM) methodology. By CM, we understand an interactive and iterative process in which stakeholder engagement and communication activities are constantly complemented by modelling and communication tools, such as a collaborative platform. Thus, CM is a socio-technical approach where the process and supportive tools are developed simultaneously and interwoven. The aim of this approach is to stimulate and support the processes of individual and social learning about the issues of concern (in this case FRM) as well as about the values, attitudes and positions of the involved stakeholders and community members. Such learning elevates the overall flood risk awareness within the communities and opens up the possibilities for participatory decision making regarding FRM, which may lead to commonly agreed FRM alternatives and strategies. As will be demonstrated later, the process of analysis, evaluation and ranking of FRM alternatives, eventually leading to selection of alternatives for actual implementation, is the focus of the CM approach introduced in this research. Alternatives are understood as sets of individual interventions in the analysed system (physical, socio-economic or administrative). Such interventions are named measures. Strategies, on the other hand, are understood as combinations of alternatives.

This method was developed and tested in the ERANETCRUE project "Decentralised Integrated Analysis and Enhancement of Awareness through Collaborative Modelling and Management" (DIANE-CM).

The specific objectives of the DIANE-CM approach are as follows:

- development of a shared understanding of current flood risk amongst stakeholders ${ }^{1}$;

- joint development and evaluation of alternatives for FRM;

- testing of flood risk alternatives under different scenarios;

- support for negotiation and selection of commonly agreed alternatives.

These objectives are developed via a CM process that has been designed, implemented and tested in two case study areas: one in Germany and the other one in the UK.

In subsequent sections, this paper presents a comprehensive overview of the complete methodology as it was developed and implemented (together with the supporting webbased tools), the results obtained from its application in the project, and the discussion of these results, which also highlights some lessons learned for future applications.

\section{Methodology}

\subsection{Background}

The main research question of the transdisciplinary DIANECM project was to investigate how active involvement of stakeholders and a social learning process can be supported by socio-technical tools and processes such as $\mathrm{CM}$.

Therefore, a socio-technical framework for conceptualization, design and development of participatory flood risk management (FRM) processes was developed. This process shall enable the processes of individual and particularly social learning of all involved actors, regarding managing flood risks. Social learning is a popular term and approach referring to many different kinds of processes of learning in different contexts where uncertainty and change are problematic

\footnotetext{
${ }^{1}$ Our understanding of stakeholders in the DIANE-CM approach is representatives of relevant authorities and institutions with a stake but also the general public with focus on citizens who are potentially affected by floods.
} 


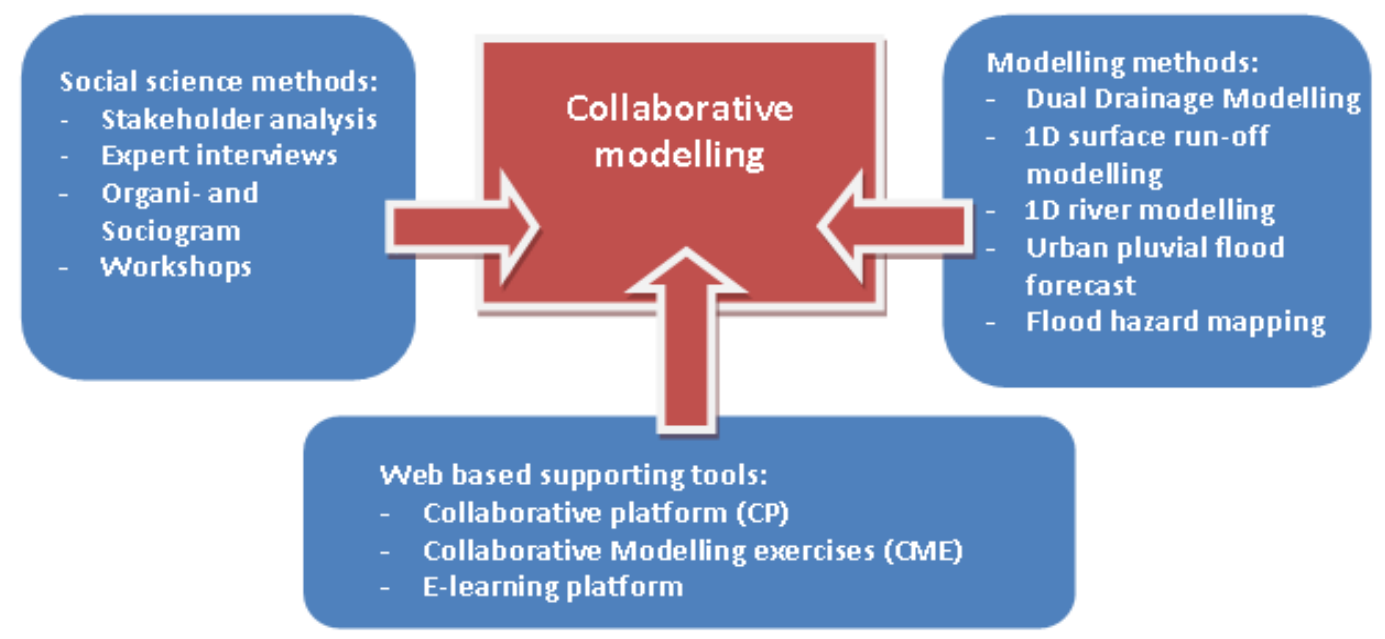

Fig. 1. Overview of the methods applied in the DIANE-CM approach.

(Pahl-Wostl et al., 2007). It is increasingly used in, for example, environmental or natural resources management, and it is regarded as a promising approach for collective decision making in societal challenges characterized by complexity, uncertainty and multiple social perspectives (e.g. Schusler et al., 2003; Kilvington, 2007; Mostert et al., 2007).

Social learning can be described as a concept where individuals and organizations learn from and about each other through exchange, dialogue or even conflict (Smith and MacGregor, 1992). Schusler et al. (2003) concluded that the term conceals great diversity, but they still defined it from different sources as learning that occurs when people engage one another, sharing diverse perspectives and experiences to develop a common framework of understanding and basis for joint action.

The social learning approach has been identified to be suitable for stakeholder participation where the knowledge about the problem at hand is very diverse, the known facts may be characterised with considerable levels of uncertainty, and the possibility of reaching a consensus (commonly agreed strategies for dealing with the problem) is not very likely. As many other domains in water- and environmental management participatory FRM fits into this category of problems. Therefore, we initiated a social learning process together with stakeholders.

The CM method is an interactive and iterative process in which stakeholder engagement and communication activities are constantly complemented by modelling and communication tools, such as collaborative platform (CP) or a collaborative modelling exercise (CME).

The realisation of social learning was supported by $\mathrm{CM}$ by means of both face-to-face workshops and interactive webbased tools tailored to the particular target group. In this process, through the activities of $\mathrm{CM}$, different stakeholders learn not only about the technical aspects of the problem at hand and its formulation (FRM in this particular case), but they learn also about the knowledge, values, interests and positions of other stakeholders involved.

For this approach, a multidisciplinary methodology was developed with three interlinked types of methods and tools: the social science methods, the modelling methods and the web-based supporting methods and tools; all these methods are interwoven into the CM concept (see Fig. 1).

\subsection{The collaborative modelling framework}

A number of current research outputs (inter alia from the FLOODsite project, www.floodsite.net) pointed out the need for the development of frameworks for a structured approach to FRM. Following the critical step of flood risk assessment (which effectively leads to identification of objectives in the management process), such frameworks usually propose steps in defining strategic alternatives (which may be comprised of combined sets of lower level measures), and evaluation and assessment of such defined alternatives. In the process of evaluation and assessment, it is always recommended that this is carried out within a limited set of scenarios, which simply comprise external (future) conditions that cannot be taken into account within the actual analysis. Alternatives need to be tested and evaluated across these different scenarios, so that more robust alternatives can be identified (those that consistently perform well in different scenarios). This generic approach is incorporated clearly in the frameworks for strategic long-term flood risk management (see Hutter et al., 2007), and it was implemented in decision support systems (DSSs) that were developed for the same purpose within the FLOODsite project (De Bruijn et al., 2008; McGahey et al., 2008).

In order to structure the CM process, a framework was developed that incorporates these research findings (illustrated in Fig. 2). The framework is structured into five steps: 
0. System definition;

1. Development of shared understanding of current flood risk and identification of FRM objectives;

\section{Definition and evaluation of external scenarios;}

3. Identification and evaluation of alternatives for FRM; and

\section{Ranking of alternatives through CME.}

Starting from current flood risk assessments (risk is defined as the product of hazard and vulnerability), objectives (usually in terms of flood risk reduction) are identified. In the next stage, possible alternatives for achieving the objectives are identified, assessed and evaluated. Then, external scenarios are identified and the alternatives are tested for their performance across these different scenarios. The final evaluation results in ranking of the proposed alternatives. Along this framework, the CM process was conducted.

The $\mathrm{CP}$ was organised along the same structure. It guides the user through a series of steps aiming at developing a shared understanding of flood risk and at preparing him/her to take part in the subsequent CME. In this exercise, stakeholders were able to rank the alternatives for FRM according to their own preferences regarding the importance of identified objectives and they were also enabled to negotiate with other participants through a virtual platform.

During the participatory activities, the stakeholders can influence and adapt the so-provided content and partly modify the functionalities of this tool for purposes of collaborative decision making. By doing so, transparency of information and results, confidence in the process and acceptance of negotiated measures can be reached, which are crucial in FRM.

The feedback provided by the stakeholders through the $\mathrm{CP}$ (especially regarding the objectives and alternatives for FRM) constitutes the basis for the final design and content of this decision-making tool used in the CME, whose purpose is to support a joint/collaborative selection of the most appropriate alternatives for managing flooding in the study area.

In the CME, the joint ranking of FRM alternatives is developed through the following 3 stages, which are supported by the online tool developed for this purpose: (1) individual profile, (2) group profile and (3) collaboration and negotiation. In the first step, each stakeholder evaluates and ranks the given FRM alternatives according to his/her own preferences. In the second step, the individual rankings are aggregated to a group ranking with transparent presentation of individual positions versus the group. The third step consists of adaptation of the group ranking by means of adjusting individual ranking of participating stakeholders, following collaboration and negotiation activities.

\subsection{Case studies}

\subsubsection{German case study: River Alster catchment}

The CM approach was applied and tested in two different case study areas; one was located in Germany and one was in UK. The German case study was in the catchment of River Alster $\left(587 \mathrm{~km}^{2}\right)$ in northern Germany where a series of flood events have taken place in the recent years. The catchment is shared by Hamburg and Schleswig-Holstein federal states, and it covers the centre of the city of Hamburg, which is vulnerable to fluvial, pluvial and coincidental flooding. The River Alster is a direct tributary to the River Elbe, which is under tidal influence at the stretch of the confluence of the two rivers. The size of the catchment is large enough to have a broad public with different social background and yet small enough to cope with the demands of shared decision making and $\mathrm{CM}$ within the 22 month duration of the project. The focus of this study was more on long- term planning of FRM alternatives and strategies.

\subsubsection{UK case study: Cranbrook catchment}

The UK case study is the small-sized urban catchment of Cranbrook $\left(9.1 \mathrm{~km}^{2}\right)$, located in the London Borough of Redbridge, in North East London. This site was selected due to the fact that it has experienced a series of severe flooding events over the last few decades, which significantly affected public buildings, commercial and residential areas, and transportation infrastructure. These floods are predominantly of pluvial nature (storms with high rainfall intensity usually occurring during summer), often coinciding with high water levels in the nearby River Roding, which constitutes the downstream boundary condition for the Cranbrook catchment. The focus of this case study was more on planning and management of emergency flood events, without neglecting long-term planning.

\subsection{Stakeholder analysis}

Stakeholder analysis is one of the key steps required in order to identify the relevant stakeholders and local champions, to understand the interrelations between them and to assess their flood risk awareness and the current situation regarding FRM in the study area. The results of this analysis constitute the basis for the design and implementation of the CM process, methodologies and tools. In order to carry out the stakeholder analysis, a framework consisting of a combination of different methods was developed. This framework is not case-specific and could easily be applied to other case studies. Through a systematic analysis, an organi- and sociogram were elaborated. It summarises the results of the stakeholder analysis (in particular the interrelations between stakeholders) and allows for a better visualisation and understanding of the results. 


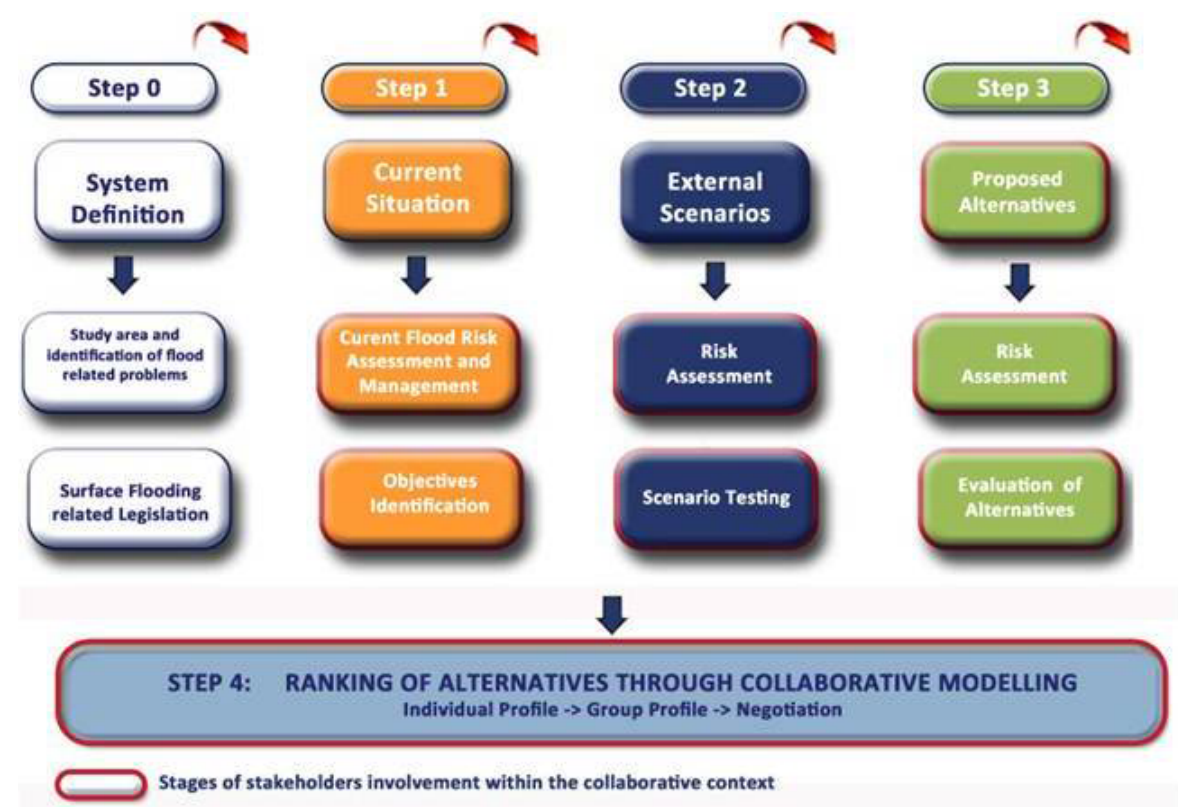

Fig. 2. Common framework for the CM approach implemented in both case studies.

One of the key tasks within the stakeholder analysis was the identification of local champions, given that they play a crucial role in the CM approach. They were expected to be mediators between the authorities and the local community members, and they were also expected to "take over" the tools developed throughout the project, in order to ensure its continuity.

\subsection{Flood modelling and mapping}

The CM approach includes flood modelling, and mapping activities provided vital input for the CM tools and for the engagement of stakeholders. An overview of the modelling activities adopted in the two case studies is next provided.

In the Alster catchment in Germany, a broad modelling approach for mid- to long-term FRM with the focus on fluvial floods for the whole catchment of the River Alster was chosen. For this purpose, hydrological and hydrodynamic models as well as GIS and Google Maps were used.

The freely available HEC-GEORAS (USACE, 2009) extension of the licenced ArcGIS software of Environmental Systems Research Institute (ESRI) was used to extract geometrical data from the DEM. The freely available HECRAS (USACE, 2010) 1-D hydraulic modelling system was used to set up a 1-D model of the downstream section of the river part (between Fuhlsbüttler sluice and Schaartorschleuse, point at which the River Alster flows into the Elbe). Furthermore, an existing hydrological model (developed in the open source Kalypso modelling system http://kalypso.bjoernsen.de) and an existing 1-D river model (developed with MIKE 11 modelling system licenced by DHI Water and Environment; Mike by DHI, 2012) for the upper part of the case study area were coupled with the HECRAS model of the downstream section of the river. The topographic and bathymetric data were provided by the LSBG (Landesbetrieb Straßen, Brücken und Gewässer - Agency for Streets, Bridges and Waters), which is responsible amongst others for flood protection in the city and federal state of Hamburg.

Although these models covered nearly the whole extent of the River Alster, it emerged from the stakeholder discussions that the focus in the project needs to be on several identified flood prone areas (so-called wet spots), which also served as locations for demonstrating the effects of some simulated FRM measures.

The modelling results were used to discuss scenarios both via the platform (online) and during the workshops. Furthermore, several extreme scenarios were simulated. These scenarios were discussed together with the stakeholders. These examples were later used in evaluating the overall FRM alternatives that could be implemented on a catchment scale. Similarly to the UK case studies, all flood hazard and vulnerability results were deployed as maps on the web-based collaborative platform using the base maps provided by Google via its freely available Google Maps application and application programming interface (API).

In the Cranbrook catchment (UK), the focus was on urban pluvial/surface flooding, a type of flooding caused by intense local storms during which the capacity of the sewer network and of the surface drainage system is exceeded. When surface flooding occurs, the sewer and the overland networks interact (i.e. water may go from the surface to the sewers and, once the sewers surcharge, water may flow from the sewers to the surface); this interaction is known as "dual-drainage 
concept" (Djordjevic et al., 2005) (see Fig. 3) and must be considered in the models if surface flooding is to be represented accurately. In addition, this type of flooding takes place quickly and at small temporal and spatial scales, making it necessary to have very detailed and, if intended for real-time forecasting purposes, fast models. It must be noted that, if the models are not intended to be used for real-time applications, but instead for planning purposes, model runtimes are not critical.

Considering these requirements, two types of physically based $^{2}$, dual-drainage surface flood models of the study area were set up and calibrated (using rain gauge, flow and depth records) in Infoworks CS (MWH, 2010) ${ }^{3}$ : a 1-D-2-D model and a 1-D-1-D one. In the 1-D-2-D approach, the surface network is modelled as a 2D (two-dimensional) mesh of triangular elements generated based on the DTM (Digital Terrain Model) of the area. The 2-D model of the surface network is coupled with the 1-D (one-dimensional) model of the sewer network, thus obtaining a 1-D-2-D model. In the 1-D-1-D model approach, the Automatic Overland Flow Delineation (AOFD) tool is used to create a 1-D model of the overland network, which is coupled with the 1-D model of the sewer network. The output of the AOFD tool is a 1-D model of the overland network which can be imported into InfoWorks CS and is coupled with the sewer network model; for details of AOFD, the readers may refer to Maksimovic et al. (2009). The 1-D-1-D dual drainage model can reproduce the behaviour of the system, while keeping computational time reasonably short; this makes it suitable for realtime forecasting of pluvial flooding. However, the 1-D-2-D model, which is much more time-consuming, is more accurate and allows for a better visualisation of the results (Allit et al., 2009); therefore, it was used to simulate flood scenarios and FRM alternatives and to generate flood hazard maps to be included in the CM platform implemented in this project.

\footnotetext{
${ }^{2}$ In physically based models, water movement over the surface and in the sewers is modelled by solving the appropriate approximation of mass and momentum conservation equations. This enables simulating the features of urban areas more realistically. The main advantage of physically based approaches is that, once the model has been calibrated, any changes in physical characteristics of the catchment (e.g. increased imperviousness due to urbanization), change of network topology, or addition/modification of pipes can be reliably described by updating the subcatchment characteristics but without the need for re-calibration of surface run-off model parameters as it would be necessary with conceptual models (Maksimoviç et al., 2009).

${ }^{3}$ InfoWorks CS is the most widely used urban drainage modelling software in the UK. In addition, it provides cutting edge functionalities and modelling elements for specifically modelling urban pluvial/surface flooding. Furthermore, the models of the Cranbrook catchment provided by the water utility of the area were already set up in this software. For these reasons, InfoWorks CS was chosen to set up the models of the UK case study used within the DIANE-CM project.
}

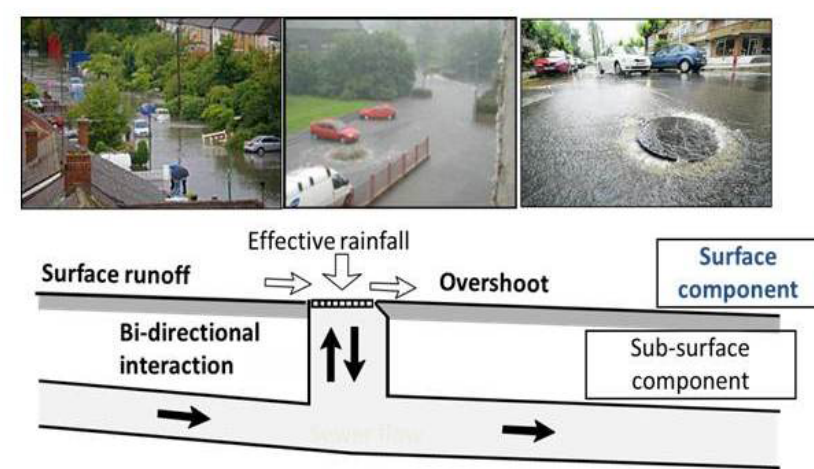

Fig. 3. Dual-drainage concept.

The flood hazard maps (displaying flood extent and depth, indicated with different colours) were deployed using Google Maps as an underlying base layer. In combination with flood vulnerability maps, this enabled the stakeholders to recognise the flood risks in a way that was familiar to them. More information on the developed maps is provided in Sect. 3.2.

\subsection{Development and implementation of the workshop series}

The workshop series were developed by regarding three criteria: (1) the CM framework, (2) different steps of the social learning elements, and (3) input from good practise examples, especially from existing experiences in stakeholder involvement for FRM in the Netherlands. Series of interviews with Dutch experts in this area were carried out in the beginning of the project, which highlighted important aspects that need to be taken into account: the need for thorough stakeholder analysis, the importance of developing sense of importance (urgency) of the flood-related problems, the careful planning and structuring of the workshop series, the need for presenting the necessary information in a customised manner to the different types of stakeholders, the critical facilitating role of experts/modellers involved in the process, etc. All these recommendations were taken into account in the subsequent design and development of the CM process and supporting tools.

A set of four workshops was conducted in both case studies. Table 1 shows the workshop concept, the purpose and the activities carried out in each workshop with the example of the Alster case study.

Table 1 provides an overview of the workshop structure in the German case study. It can be derived from the table that the workshop series allowed a progressive realisation of the FRM objectives as defined in the DIANE-CM framework (see Fig. 2). The activities in the single workshops were strongly dependent on the input of the participants, their experiences and interests. Accordingly, the information provided on the $\mathrm{CP}$ and in the workshops was updated 
Table 1. Timeline and objectives of CM workshops (example Alster/Germany).

\begin{tabular}{|c|c|}
\hline EVENT \& PURPOSE & ACTIVITIES \\
\hline Kickoff (November 2010) & $\begin{array}{l}\text { - Information of the stakeholders and the regional public on purpose } \\
\text { and setting of the project } \\
\text { - Stimulate to participate either in the workshops or online }\end{array}$ \\
\hline $\begin{array}{l}\text { 1st workshop } \\
\text { Information and learning about } \\
\text { interest and needs of stakeholders } \\
\text { (December 2010) }\end{array}$ & $\begin{array}{l}\text { - Clarification of terms and boundary conditions for process } \\
\text { - Info and discussion on online-participation/workshops } \\
\text { - Discussion of current hazard/ hazard maps } \\
\text { - Feedback on model results/elicitation of local knowledge } \\
\text { - Discourse on objectives for FRM in the catchment } \\
\text { - Definition of scenarios } \\
\text { - Further ideas, proposals etc. }\end{array}$ \\
\hline $\begin{array}{l}\text { 2nd workshop } \\
\text { Discussion/Discourse } \\
\text { (February 2011) }\end{array}$ & $\begin{array}{l}\text { - Discourse on simulated scenarios, brainstorming on possible } \\
\text { measures, discussion, trade off } \\
\text { - Identification and description of neuralgic points ("wet spots") } \\
\text { - Identification of alternatives/re-defining objectives } \\
\text { - Identification possible measures for "wet spots" } \\
\text { - Input from online-participation }\end{array}$ \\
\hline $\begin{array}{l}\text { 3rd workshop } \\
\text { Negotiation } \\
\text { (March 2011) }\end{array}$ & $\begin{array}{l}\text { - Identification of possible measures for "wet spots" } \\
\text { - Discussion and trade off of different alternatives/impacts of measures } \\
\text { - Conclusion on measures and implementations } \\
\text { - Input from online-participation }\end{array}$ \\
\hline $\begin{array}{l}\text { 4th workshop } \\
\text { Conclusion \& Wrap-up } \\
\text { (May 2011) }\end{array}$ & $\begin{array}{l}\text { - Conducting the exercise of CM (CME) } \\
\text { - Ranking of alternatives } \\
\text { - Negotiation and conclusion on measures and implementations }\end{array}$ \\
\hline
\end{tabular}

(including updated modelling results) and adjusted based on stakeholders' input.

\subsection{Collaborative platform for shared understanding of flood risk}

One of the main purposes of the CM approach is to make flood management decision making more participatory by developing a shared understanding of flood risk and supporting the interaction between local stakeholders. Given the limitations of face-to-face workshops and stakeholder meetings (in terms of time and resources), the project took the approach of supporting these processes continuously via a web-based collaborative platform that was progressively developed during the period covered by the stakeholders workshops. Stakeholders could influence the content and the form of the collaborative platform and to some extent the functionalities of the tool for shared decision making (the CME). By taking this approach, full transparency of information and results was provided. This also increased the confidence in the process and generated high level of acceptance of negotiated measures, which are crucial conditions for successful participatory FRM.

The collaborative platform is conceptually designed to guide the user through a series of steps aiming at developing a shared understanding of flood risk and at preparing him/her to take part in the subsequent CME. The steps through which the user is guided are in fact the same as those presented earlier in Fig. 2. For each step, the collaborative platform contains structured information presented via documents, animated and interactive maps and graphs and similar visual information. The same concept was applied for both case studies, but, given the differences in the local characteristics and different languages used of Alster and Cranbrook case studies, in fact two different collaborative platforms were developed and used.

\subsection{Collaborative modelling exercise (CME)}

In the final stage of this collaborative process, a participatory web-based decision-making instrument was implemented as an additional feature of the main collaborative platform. The feedback provided by the stakeholders through the main collaborative platform (especially regarding the objectives and alternatives for FRM) constitutes the basis for the final design of this decision-making tool, whose purpose is to support a joint/collaborative selection of the most appropriate alternatives for managing flooding in the study area.

The implemented CME is valuable because of its obvious direct link to possible FRM decisions in the real world with participation of actual stakeholders. Additionally, framing the collaboration among stakeholders within 
a decision-making framework, with clearly established goal (towards a selection of a given alternative for implementation), leads to more effective individual and social learning. These are the key reasons behind the CME implementation. Participatory decision making in water- and environmentrelated problems has been researched extensively during the last decade, usually by focussing on particular aspects of the problem. For example, Jankowski (2000, 2009) discussed the need for customised map-based presentation of knowledge for diverse stakeholders engaged in participatory decision making, using multi-criteria analysis (MCA) methods by groups. The theory and application of such methods together with negotiation steps in water resources have been summarised by Soncini-Sessa $(2007 a, b)$. The potential of web applications for implementing such methods has also been investigated, e.g., by Zhu and Dale (2001) and Mustajoki et al. (2004).

Following the concepts initially developed by Jonoski (2002), the CME implemented here aims to integrate all these aspects (customised knowledge presentation, MCA methods and taking advantages of the web). In CME the joint ranking of FRM alternatives is developed through the following 3 stages, which are supported by the online tool developed for this purpose: (1) Individual Profile, (2) Group Profile and (3) Collaboration and Negotiation. In the first step each stakeholder develops evaluation and ranking of alternatives according to own preferences regarding the identified objectives. The evaluation is carried out by extensive use of the customised flood-related maps. For ranking of the alternatives the Fuzzy TOPSIS method (Technique for Order Preferences by Similarity to Ideal Solutions), (Chen and Hwang, 1992) was implemented as a web application. This is a particular multi-criteria analysis method which enables ranking of alternatives using both quantitative and qualitative expressions of alternative performance regarding the identified objectives. The qualitative expressions are made by using linguistic terms, which are subsequently converted in fuzzy numbers used for the calculations of the rankings. The TOPSIS method calculates so called scores of alternatives (based on calculated distances from ideal solutions), which provide the actual ranking. In the second step the individual rankings are aggregated to a group ranking with transparent presentation of individual positions versus the group. Standard aggregation procedure based on sums of ranking points from individual rankings (the so-called Borda score, see, for example Hwang and Lin, 1987) were used for presenting the group ranking in tables and bar charts. Modified aggregations using the scores of the alternatives were used for providing clearer representation of relative individual positions within the group. Such representation was provided with specially developed visualisation tools. Finally the third step consists of adaptation of the group ranking by means of adjusting individual ranking of participating stakeholders, following collaboration and negotiation activities. For this purpose a chat-like interface was provided, which together with the fully transparent presentation of the individual and group profiles enables the participants to engage in discussions and negotiations. The actual use of the CME tools by the stakeholders in the two case studies was carried out during the final workshops and subsequently online.

\subsection{E-learning platform}

A further web-based tool included in the CM approach was a separately developed e-learning platform, where structured learning material was provided on various FRM topics. Knowledge from the project as well as from outside was collected, organised and made available online to a variety of stakeholder groups in the form of short courses. The platform currently allows access to education and training material collected and/or developed in the project, in an organised fashion, designed to allow for collaboration between "trainers" and "trainees" through a variety of online environments including forums, chats and e-classes (Makropoulos et al., 2009). The structuring of the courses targets four different groups: (a) planners (b) modellers (c) real-time operators and emergency managers and (d) general public. A separate short course with different material for each target group was developed for this purpose: the course for planners focused on planning guidelines, the link between planning and risk mapping and available FRM measures. The course for modellers introduced advanced data management topics, innovative flood simulation approaches and risk map creation, while the course for real-time operators focused on issues of realtime rainfall prediction, flood control as well as methods and tools for emergency planning. Finally, the course targeting the general public exposed the trainees to actions that can be taken before, during and after a flood, as well to issues and approaches for community engagement and active participation in FRM. The e-learning platform was developed using the open source Moodle content management system (www.moodle.org).

\section{Results - implementation of the collaborative modelling framework}

In this section, we will present the specific results achieved from the implementation process of the framework for $\mathrm{CM}$ (cf. Fig. 2). The description will more or less follow the steps from system definition (step 0), current situation (step 1), external scenarios (step 2), alternatives (step 3) and the collaborative modelling exercise (step 4).

As explained earlier, the approach of $\mathrm{CM}$ is a sociotechnical approach where the process and supportive tools are developed simultaneously and interwoven. Thus, before the description of the respective steps, the process and the collaborative platform as a socio-technical instrument will be illustrated. 


\subsection{The process - development and implementation of the workshop series}

In order to facilitate face-to-face interaction with and amongst the stakeholders, a series of workshops was conducted in both case study areas as described in Table 1.

\subsubsection{Germany - Alster case study}

In the Alster catchment a kick-off meeting and a series of four workshops were conducted between November 2010 and March 2011, all arranged in the city of Hamburg (cf. Table 1). The workshops were essential elements of the social learning process since, within these meetings, lively discussions and interdisciplinary exchange were realised. The workshops were structured in a sequenced way, whose structure could briefly be summarised as follows: In the first workshop, the group discussed the current flood risk situation in the Alster catchment (cf. step 1 in Fig. 2), whereby the exchange of experiences and knowledge of the stakeholders was crucial. In between the first and second modelling session, stakeholders had the possibility to use the collaborative platform to supplement and comment the FRM objectives, the proposed alternatives and scenarios as well as the wet spots that were identified during the first workshop. The results of this online consultation were valuable input to the second workshop held in January 2011. Besides the discussion about and specification of FRM objectives, scenarios and alternatives for the workshop series, and first simulation results at exemplary wet spots were presented and possible measures to reduce flood risk at these neuralgic spots were discussed (cf. step 1 to step 3 in Fig. 2). In the third workshop, the participants discussed the identified alternatives and the measures grouped into these alternatives. Furthermore, simulation results were presented through the project team and discussed among the participants (cf. step 2 and step 3 in Fig. 2). In the last workshop session, conclusions for FRM in the Alster catchment were drawn and the CME (cf. 3.5) was conducted (cf. step 4 in Fig. 2). For all workshops, minutes were taken and published on the CP.

The following primary and secondary stakeholders (see also Sect. 3.3, step 0) participated in the German workshop series: state and regional water management authorities from Hamburg and Schleswig-Holstein, Hamburg state planning authority, environmental NGOs, Hamburg fire brigade, water maintenance associations from Schleswig-Holstein, and potentially affected residents.

Within the CM process, these stakeholders were working together to improve the flood management situation in the Alster catchment. Unfortunately, some of the primary stakeholders (e.g. the regional spatial planning authorities) were not able to participate.

The evaluation of workshop series carried out that the residents especially appreciated the possibility to discuss FRM issues with representatives of the authorities. The stakeholders in general valued the interdisciplinary discourse and exchange on specific local problems. All participants regarded the visualisation of the simulated effects of implemented measures as interesting and helpful for assessing FRM option.

\subsubsection{UK - Cranbrook case study}

In the UK, a total of five sessions were held. All of them, except for the forth one, took place at Imperial College London. Representatives from all relevant stakeholder groups and institutions attended the first three meetings; this included representatives from the different teams of the Redbridge Local Council (including the Emergency Planning, Highways and Engineering and Planning Policy teams), the London Fire Brigade, the Environment Agency, Thames Water and the local community. The first brainstorming session served as first approach to the stakeholders and enabled us to understand the current situation regarding FRM in the study area, as well as the stakeholders' concerns and interests (cf. step 1 in Fig. 2). The second and third meetings were exclusively focused on the CM platform and exercise. In these two meetings, guidance for the use of the platform and the development of the exercise were provided at the beginning and later on all stakeholders took part in the planned activities and in the CME via the collaborative platform, whose final result was the joint ranking of alternatives for surface FRM in Redbridge. At the end of each of these sessions, it was possible to discuss the experience and the results as well as to obtain feedback from the participants (special feedback questionnaires were designed for this purpose). The forth and fifth meetings were smaller, and only the local champions took part in it. The main purpose of these meetings was to discuss with the local champions the findings and lessons learned throughout the project and transfer them the knowledge generated from it. This was essential in order to ensure applicability and continuity of the project deliverables. The local champions were very interested in the results and found the tools and knowledge generated throughout the implementation of the CM approach very helpful. In conclusion, it can be said that interaction between stakeholders in fact took place in the collaborative workshops and the activities and tools used in these sessions enabled CM for improved management of flood risk in the study area.

\subsection{The collaborative platform as a socio-technical instrument}

Based on the information collected from the stakeholder analysis, from the collected experiences in The Netherlands and from literature and legislation review, a tailor-made collaborative platform for shared understanding of flood risk was developed for each case study area. This platform can be accessed from the following links: http://hikm.ihe.nl/ 
diane_cm/alster/ for Alster (Germany) and http://hikm.ihe.nl/ diane_cm/cranbrook/ for Cranbrook (UK).

While details about the collaborative platforms can be obtained from the above-provided links, here we deliver a brief summary of the structure and the available sections of the collaborative platform (available as menu items from the horizontal navigational menu) which are the same for both case studies. These sections are as follows:

- introduction (description of the project aims, links to user feedback components);

- case study area description (description of flooding issues for each case study);

- flood risk framework (existing FRM approach, actors, responsible institutions, including legislation);

- FRM (description of the FRM framework, as in Fig. 2, links to each step of the framework where relevant information and modelling results are presented);

- stakeholders (description of all stakeholders and their categorisation);

- CM (link to the interfaces for CME, after registration and login).

With this structure, the users are introduced to the full FRM context, the FRM steps and the identified scenarios, objectives and alternatives used in the CME.

The information presented on the platform was continuously updated during the $\mathrm{CM}$ process. Interactive maps and simulations results, developed during the process, were integrated and a forum for interactive communication was embedded.

\subsection{Implementation of the CM framework - step 0 to step 4}

The implementation of the CM framework was based on five steps, of which the later three are closely interwoven. It starts with the system definition.

\subsubsection{Step 0 - system definition}

In the preparatory step for a $\mathrm{CM}$ process, a system definition is crucial to be undertaken. In our context, the stakeholder analysis and setting up the flood modelling and mapping for FRM were undertaken as part of the system definition. The development of the maps is not only relevant for the system definition but also for the following step, the description of the current situation.

\section{Stakeholder analysis}

For both case studies, lists of relevant stakeholders were prepared and representatives of main stakeholders were interviewed during June, July and August 2010. In the UK
26 relevant local stakeholders were identified and 11 interviews were carried out. In Germany, 46 relevant stakeholders were identified and 19 interviews were conducted. The information collected from the interviews was summarised in a parameter table. Based on the results of structured interviews, through the stakeholder analysis and based on the information collected from the first workshop (brainstorming session) and kick-off event respectively, the stakeholders were classified into four categories and their interactions were analysed:

1. Local champions: main institutions coordinating flood risk and event management; they either produce or centralise information and pass it on to other stakeholders.

2. Primary stakeholders: these stakeholders are highly relevant in FRM and flood emergency management; they usually get information and instructions from the local champions.

3. Secondary stakeholders: either private/public/governmental institutions who play a significant role in facilitating FRM.

4. Tertiary stakeholders/multiplicators: community members, community organisations, schools and other organisations. These stakeholders are likely to be affected by flooding, and they also could play a very important role as multipliers of flood prevention measures/awareness in their community.

The results of this analysis and categorisation in the respective case study areas are as follows:

\section{Germany - Alster case study}

1. Local champions: representative from the Agency for Streets, Bridges and Waters in Hamburg

2. Primary stakeholders: state authorities in Hamburg and Schleswig-Holstein (water management, spatial planning, nature conservation), regional administration in Hamburg and Schleswig-Holstein (water management, spatial planning), environmental-NGOs in Hamburg, water maintenance associations in Schleswig-Holstein, water supply and disposal company Hamburg

3. Secondary stakeholders: residents, political bodies on state and regional level, regional environmental-NGOs in Schleswig-Holstein, farming and angling associations, Civil protection authorities, municipalities in Schleswig-Holstein, utility and traffic companies, regional business and companies, citizen, sport and allotment clubs

4. Tertiary stakeholders/multiplicators: schools, nurseries, religious groups 
This list is indicative that the focus of the Alster case study was laid more on long-term and catchment-wide FRM alternatives and strategies.

\section{UK - Cranbrook case study}

1. Local champions: identified representatives from the Environment Agency and the Redbridge Emergency Planning Department.

2. Primary stakeholders: Redbridge Fire Brigade, Metropolitan Police Service, Thames Water, Redbridge Highways and Engineering Department, Local Council as a whole.

3. Secondary stakeholders: Redbridge Planning Department, local councillors, National Express (Railway operator), transport for London.

4. Tertiary stakeholders: local community groups (e.g. Maybank Association, Broadmead Road Baptist Church, NHS general practitioners, other local religious groups), schools, libraries, community residents, private businesses and other utilities (e.g. gas, electricity).

The list of stakeholders reflects the main focus of this case study, which was planning and management of emergency flood events.

As part of the stakeholder analysis, the interrelations and the flows of information, cooperation and potential conflicts among the identified stakeholders were identified and organised into organi- and sociograms, as in Fig. 4, which shows the example for the UK case study area (Cranbrook).

Similar sociograms were also developed for the German case study (Alster). This information was helpful in clarifying the FRM roles and responsibilities of different stakeholders and highlighting potential for improvements in cooperation, which was subsequently further emphasised during the workshop series.

\section{Flood modelling and mapping}

\section{Germany - Alster case study}

The developed model (see Sect. 2.5) of the River Alster was used to simulate different flood scenarios and FRM alternatives, which provided flood hazard maps that were used in the CM process with the stakeholders. The alternatives and the scenarios modelled will be presented in step 2 and 3 . An example of one such flood hazard map is presented in Fig. 5.

Flood hazard maps, based on the $100 \mathrm{yr}$ and $200 \mathrm{yr}$ return period event respectively, were produced as basic information on current hazard levels. The $100 \mathrm{yr}$ flood scenario is demanded by the EU Flood Directive; the $200 \mathrm{yr}$ flood scenario is the basic scenario for the states of Hamburg and Schleswig-Holstein. The flood depths simulated for each flood scenario were exported as shapefiles and were post-processed in ArcGIS in order to develop the corresponding flood hazard maps. Based upon the hazard map potential, economic damage was calculated including information on replacement costs. This information was not displayed in maps but was only used for qualitative assessments, since the quality and resolution of these data were not valid enough. Critical infrastructures such as kindergartens, schools and underground stations were integrated into this analysis by their identification and visualisation in the maps

\section{UK - Cranbrook case study}

In order to simulate the flood scenarios and flood risk management alternatives, a 1-D-2-D urban pluvial flood model of the Cranbrook catchment (setup in InfoWorks CS) was used. The results constitute the basis of the maps included in the CP.

The flood depths estimated for each flood scenario were exported as shapefiles and were post-processed in ArcGIS in order to create the corresponding flood hazard maps (on which flood extent was indicated and different flood depths were assigned different colours). In addition, layers containing information about location and type of properties (i.e. commercial and residential), roads and critical infrastructure (e.g. schools, hospitals, transport infrastructure, fire brigade, police stations, etc.) were added to the maps; these elements represent "exposure" ${ }^{4}$, and when mapped together with the flood extent, they can convey an idea of flood risk (i.e. an idea of the potential consequences of the flood event on the properties and other infrastructure of the area). In this way, both flood hazard and risk were represented in a single map. The resulting hazard and risk maps were included in the CP, and Google Maps were used as background (therefore, the functionalities of Google Maps can be used when visualising the generated maps, e.g. zooming, satellite view, map view, etc.). In addition, several tools were provided so that the user can choose the information that he/she wants to display in the map (e.g. flood extent, flood risk management alternative, location of properties and critical infrastructure, etc.). This was also the case for the Alster case study.

The flood hazard and risk maps were tailored to support the evaluation of the different flood risk management alternatives in terms of each objective. More details and examples

\footnotetext{
${ }^{4}$ Exposure: people, property, systems, or other elements present in hazard zones that are thereby subject to potential losses (ISDR, 2009). It can be quantified in terms of the number of the receptors that may be influenced by a flood (Gouldby and Samuels, 2004). Measures of exposure can include number of people and their demographics, number of businesses or types of assets in an area, number and type of properties, etc.
} 


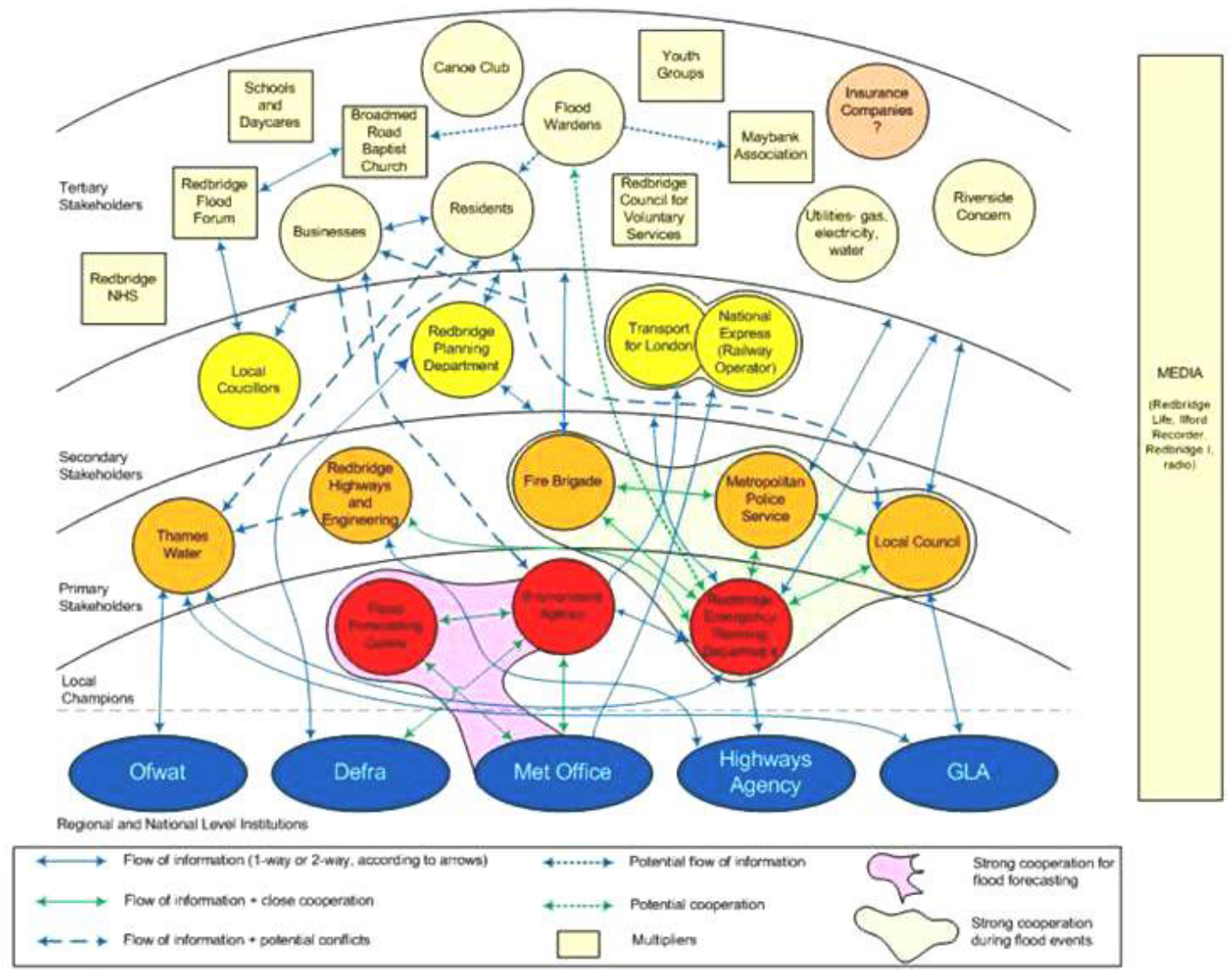

Fig. 4. Organi- and sociogram for the UK case study.
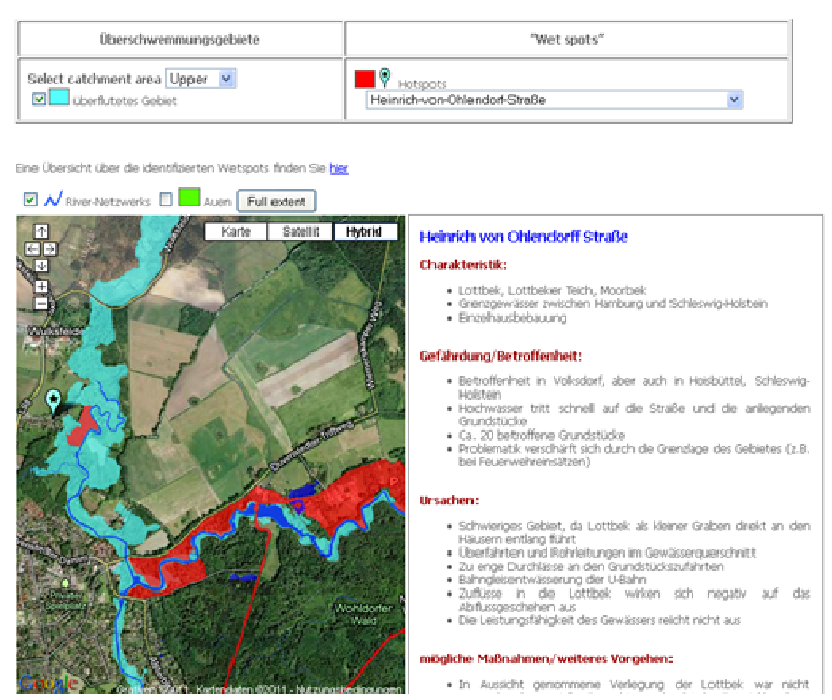

Fig. 5. Flood hazard maps displaying flood extent and depth and "wet spot" description in the collaborative platform, using Google Maps for visualising the topography. of the resulting maps describing the current situation are provided in step 3 .

\subsubsection{Step 1 - current situation}

As an important phase, the current specific flood risk was analysed in the two case study areas. Neuralgic points prone to flooding (the so-called "wet spots") were identified, modelled, information on the "wet spots" improved and adapted based on the input from local knowledge from the stakeholders. This spatial information was supplemented by additional data such as affected estates, special characteristics or measures already implemented. The data information and maps were published on the CP.

Additionally, the respective objectives for FRM were formulated and agreed upon for each case study area.

\section{Objectives}

\section{Germany - Alster case study}

In Alster, the focus was on long-term and catchment-wide alternatives for managing flood risks. Detailed analysis (including modelling) of all possible measures and alternatives in the catchment was far beyond the scope of this project. 
Consequently, more general objectives were considered for the CM process:

1. to reduce the magnitude of surface flooding;

2. to minimise negative impacts on the ecology;

3. to minimise costs of implementation.

The selection of these objectives reflects the general nature of the CME and the preferences of the involved stakeholders. All objectives were assessed in qualitative manner using descriptive text terms. The last objective (costs of implementation) was also assessed qualitatively, but these assessments were provided by experts from LSBG and individual stakeholders could not change them.

\section{UK - Cranbrook case study}

In Cranbrook, the focus was on FRM for managing emergency situations during a flood event. With this focus in mind and after consultation with the stakeholders, the following FRM objectives were identified:

1. to reduce magnitude of surface flooding;

2. to minimise damage to properties;

3. to minimise damage to critical infrastructure;

4. to maximise the opportunity to salvage belongings located in properties and businesses;

5. to select FRM alternatives that are easy and feasible to be implemented.

Objectives 1 and 2 could be assessed by quantitative indicators (1: flooded area with flood depth above $30 \mathrm{~cm} ; 2$ : number of flooded properties), by overlaying modelling results in terms of flood extent and flood depth over property maps. Objectives 3-5 could be assessed qualitatively, by using descriptive text terms. Nevertheless, the stakeholders were provided with flood hazard maps that could assist them in forming their assessment (e.g. by overlying flood hazard maps with maps of critical infrastructure). All this information was provided via interactive map-based interfaces.

\subsubsection{Step 2 - external scenarios}

After formulation of the objectives, the next step is identification of FRM scenarios, which are understood as different external extreme conditions.

\section{Germany - Alster case study}

In order to estimate the effects of different flood events and conditions in the Alster catchment, the following flood scenarios were simulated and analysed:
- Scenario 1: $100 \mathrm{yr}$ return period event

- Scenario 2: $200 \mathrm{yr}$ return period event

- Scenario 3: $200 \mathrm{yr}$ return period event + pump failure at Schaartorschleuse

- Scenario 4: $200 \mathrm{yr}$ return period event + gate failure at Schaartorschleuse + high tide at River Elbe

As mentioned before, floods with a $100 \mathrm{yr}$ return period are one of the basic scenarios required to simulate by the EU Flood Directive; the $200 \mathrm{yr}$ return period event is the basic scenario for the states of Hamburg and Schleswig-Holstein. Scenarios 3 and 4 are extreme or very extreme scenarios with very low probability of occurrence. They were used for illustrating possible impacts. The simulation of scenario 4 was suggested by the stakeholders.

\section{UK - Cranbrook case study}

In the Cranbrook case study, the following flood scenarios were simulated in order to understand the effects of different flood events and conditions in the catchment:

- Scenario 1: $30 \mathrm{yr}$ return period event + low level at the River Roding

- Scenario 2: $30 \mathrm{yr}$ return period event + high level at the River Roding

- Scenario 3: $200 \mathrm{yr}$ return period event + low level at the River Roding

- Scenario 4: $200 \mathrm{yr}$ return period event + high level at the River Roding

These scenarios were defined through discussion with local lead flood authorities of the study area, taking into account current UK flood regulations, the sources of flooding in the Cranbrook catchment and the likelihood of occurrence of the conditions comprised by each scenario. A short explanation of the parameters that were chosen to create the above scenarios is presented in Table 3 .

As can be inferred, Scenario 4 is the most critical one. It was used as reference to evaluate the performance of the different alternatives for FRM.

\subsubsection{Step 3 - alternatives}

In line with the definition of objectives and the development of the external scenarios, alternatives for FRM were set up. These FRM alternatives are combinations of measures that can be implemented for reducing flood risk in the two case study areas. They were developed based on the stakeholders' input. By comparing two alternatives, the effects on the dimension of flood prone areas were assessable quantitatively and area-related. 
Table 2. Proposed alternatives for FRM in the Alster catchment.

\begin{tabular}{|c|c|}
\hline ALTERNATIVE & $\begin{array}{l}\text { MODELLING EXAMPLE/DESCRIPTION OF THE } \\
\text { ALTERNATIVE }\end{array}$ \\
\hline A1 Do nothing (base case) & Current situation, no measures are implemented \\
\hline \multicolumn{2}{|l|}{ A2 Technical measures } \\
\hline \multicolumn{2}{|l|}{ Modification of hydraulic structures } \\
\hline & $\begin{array}{l}\text { - Lower crest level of weir at Fuhlsbüttler Schleuse } \\
\text { - Lower crest level of weir at Wohldorfer Schleuse }\end{array}$ \\
\hline Construction of reservoirs & Build dike around Hoopwischen village \\
\hline \multicolumn{2}{|l|}{ A3 Management of the catchment area } \\
\hline Sustainable and careful maintenance of water systems & $\begin{array}{l}\text { e.g. clear trees from River Ammersbek, a tributary of } \\
\text { the Alster }\end{array}$ \\
\hline $\begin{array}{l}\text { Wetland restoration (retention through activation of nat- } \\
\text { ural retention areas) }\end{array}$ & $\begin{array}{l}\text { e.g. Duvenstedter Brook, further retention wetlands ly- } \\
\text { ing in the upper parts of the catchment }\end{array}$ \\
\hline \multicolumn{2}{|l|}{ A4 Prevention } \\
\hline Improved coordination & $\begin{array}{l}\text { Coordination of responsibilities between authorities and } \\
\text { other stakeholders }\end{array}$ \\
\hline (Private) property protection & Flood protection measures at the household level \\
\hline Forecast/information & $\begin{array}{l}\text { Installation/improvement of predictive mechanisms, in- } \\
\text { formation of local residents }\end{array}$ \\
\hline
\end{tabular}

\section{Germany - Alster case study}

The different potential FRM alternatives that were identified for the Alster catchment are summarised in Table 2.

Most of the alternatives correspond to a combination of individual measures. The potential measures for FRM were defined through discussion with workshop participants and also based on the feedback provided via the collaborative platform and e-mail. It is important to note that in this case not all measures could be modelled so that the alternatives would be supported by comprehensive and complete flood hazard and risk maps for the whole catchment. Such results were provided for several of the critical wet spots, from where the effects of certain measures could be assessed.

For the simulated measures, the results of the simulations could be analysed via interactive maps as shown in Fig. 6 .

\section{UK - Cranbrook case study}

The FRM alternatives that were considered for the Cranbrook catchment are summarised in Table 4 .

The interfaces were set in such a way that the stakeholders could make pair-wise comparison of alternatives with respect to any of the identified objectives. An example of such an interface is presented in Fig. 8.

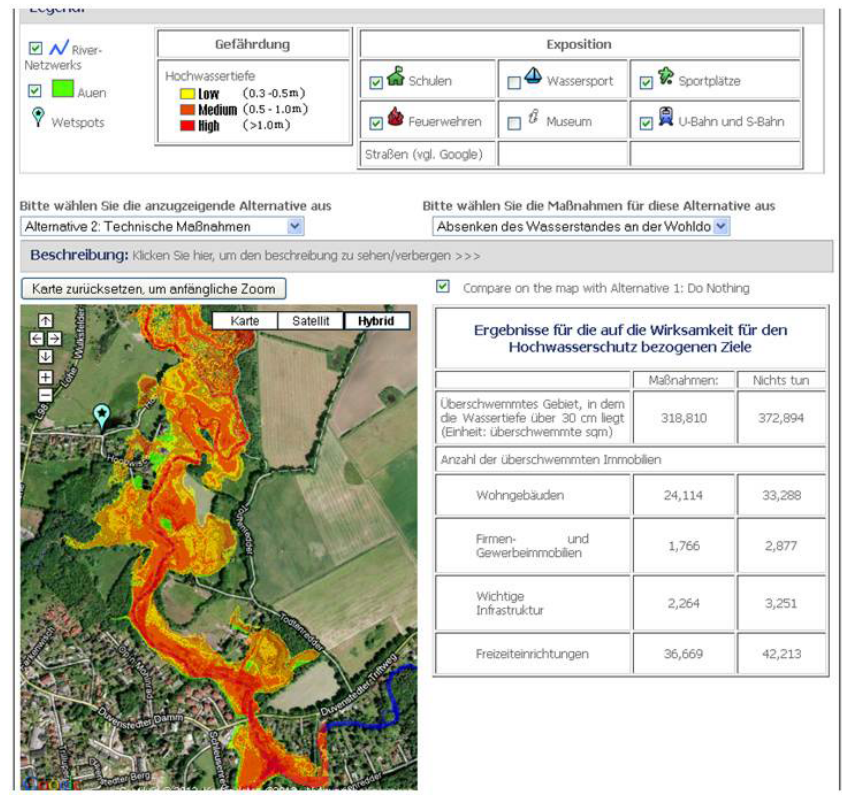

Fig. 6. Example of analysing effects of simulated measures in Alster catchment. The depth of flooding is shown in three steps $(0.3-0.5 \mathrm{~m}$, $0.5-1 \mathrm{~m},>1 \mathrm{~m})$. The difference between the current situation and simulated alternative 2 is described by flooded area given in $\mathrm{m}^{2}$. 
Table 3. Rationale behind the parameters chosen to create flood scenarios for the Cranbrook catchment (UK).

\begin{tabular}{|c|c|c|}
\hline PARAMETER & ADOPTED VALUE & RATIONALE \\
\hline $\begin{array}{l}\text { Return period or probability of } \\
\text { occurrence* }\end{array}$ & $\begin{array}{l}-30 \mathrm{yr} \text { (the probability of } \\
\text { occurrence in any year is } \\
\text { approximately } 3 \% \text { ) } \\
\text { - } 200 \mathrm{yr} \text { (the probability of } \\
\text { occurrence in any year is } \\
\text { approximately } 3 \% \text { ) }\end{array}$ & $\begin{array}{l}\text { These are the return periods used for the "Flood Maps } \\
\text { for Surface Water" (FMfSF), which have been recently } \\
\text { produced by the Environment Agency. We want our sce- } \\
\text { narios to be comparable and compatible with the most } \\
\text { recent UK regulations. } \\
\text { The reason why these return periods were chosen to } \\
\text { generate the new FMfSF is the following: } \\
\text { - The } 30 \text { yr return period event is a more probable } \\
\text { event, which is likely to produce inundation in } \\
\text { the majority of urban areas of England and Wales. } \\
\text { Furthermore, this return period is commonly used } \\
\text { as standard for urban drainage design. } \\
\text { - The } 200 \text { yr return period event corresponds to a } \\
\text { rarer event, which enables testing a more critical } \\
\text { condition. }\end{array}$ \\
\hline Rain profile & Summer rain profile & $\begin{array}{l}\text { Summer storms are more intense than winter storms and } \\
\text { are more likely to generate surface flooding, which is } \\
\text { the focus of the UK case study. }\end{array}$ \\
\hline $\begin{array}{l}\text { Water level at the Roding River } \\
\text { (at the downstream end of the } \\
\text { Cranbrook catchment) }\end{array}$ & $\begin{array}{l}\text { - Low water level } \\
\text { - High water level }\end{array}$ & $\begin{array}{l}\text { The Roding River is located in the downstream end of } \\
\text { the Cranbrook catchment. When the water level at the } \\
\text { Roding River is high, a backwater effect (water from } \\
\text { the river entering the sewer system of the Cranbrook } \\
\text { catchment) can take place, thus reducing the capacity } \\
\text { of the drainage system and causing more critical surface } \\
\text { flood events in Cranbrook. } \\
\text { Based on historical records, we picked two different } \\
\text { water levels at the Roding River which enabled under- } \\
\text { standing the effect of the river on the behaviour of the } \\
\text { Cranbrook catchment (regarding surface flooding). }\end{array}$ \\
\hline
\end{tabular}

* The design rainfall events were taken from the UK Flood Estimation Handbook (FEH) (Centre for Ecology and Hydrology, 1999).

Example: Maps created to illustrate the results of the evaluation of flood risk management alternatives in terms of $\mathrm{Ob}-$ jective 2

- Objective 2: to minimise the damage to properties

- Indicator: number of properties flooded

- Type of indicator: quantitative - the evaluation is based on the results of the flood model and the user cannot modify these results

- Main information displayed on the map:

- Flood hazard, as represented by flood extent and depth: three ranges of flood hazard (i.e. low, medium and high) were defined following international as well as UK standards, and each of them was assigned a different colour code. The established ranges can be seen in the top left corner of Fig. 7. By checking or unchecking this option, the user can choose whether or not to display the flood extent and depth on the maps.

- Exposure, as represented by the location and type of properties (i.e. commercial or residential) affected by flooding. A threshold of $30 \mathrm{~cm}$ was used to determine the properties at risk of flooding. This threshold was adopted following the recommendations set in recent documents by the UK Environment Agency, according to which the $30 \mathrm{~cm}$ threshold represents a typical value for the onset of significant property damages when property flooding may start (above doorstep level) (EA, 2010 unpublished).

- The combination of flood hazard and potentially affected properties gives an indication of the potential consequences of a given flood event; therefore, the created maps represent flood risk in addition to flood hazard. 
Table 4. Proposed alternatives for FRM in the Cranbrook catchment.

\begin{tabular}{|c|c|c|}
\hline ALTERNATIVE & TYPE OF MEASURE & DESCRIPTION \\
\hline A1 Do nothing & - Base case & $\begin{array}{l}\text { Current situation. This will be used as base } \\
\text { point for comparing and assessing the perfor- } \\
\text { mance of the proposed measures. }\end{array}$ \\
\hline A2 Rainwater harvesting & $\begin{array}{l}\text { - Mitigation measure at source level } \\
\text { - Structural measure }\end{array}$ & $\begin{array}{l}\text { It reduces runoff or flow entering the system. } \\
\text { Rainwater harvesting has been selected as one } \\
\text { of the few SUDS that can be retrofitted into the } \\
\text { existing built-up area. }\end{array}$ \\
\hline $\begin{array}{l}\text { A3 Improved and targeted } \\
\text { maintenance regimes for the } \\
\text { sewer system }\end{array}$ & $\begin{array}{l}\text { - Mitigation measure at pathway } \\
\text { level } \\
\text { - Non-structural measure }\end{array}$ & $\begin{array}{l}\text { After identifying locations that are at greatest } \\
\text { risk of flooding, targeted maintenance at the } \\
\text { critical points can be carried out. }\end{array}$ \\
\hline $\begin{array}{l}\text { A4 Improved resistance for pre- } \\
\text { venting water from entering } \\
\text { properties }\end{array}$ & $\begin{array}{l}\text { - Mitigation measure at receptor } \\
\text { level } \\
\text { - Non-structural measure }\end{array}$ & $\begin{array}{l}\text { Resistance measures prevent water from enter- } \\
\text { ing the property. It is useful for managing resid- } \\
\text { ual risk. In this case, the effect of sandbags or } \\
\text { FloodSax }{ }^{\circledR} \text { placed at the household level was } \\
\text { modelled and analysed. }\end{array}$ \\
\hline $\begin{array}{l}\text { A5 Improved rainfall and flood } \\
\text { forecasting and warning }\end{array}$ & $\begin{array}{l}\text { - Mitigation measure at receptor } \\
\text { level } \\
\text { - Non-structural measure }\end{array}$ & $\begin{array}{l}\text { With the technology we are currently develop- } \\
\text { ing, it will be possible to provide site-specific } \\
\text { real-time rainfall and surface water flood fore- } \\
\text { cast. This could be integrated to the Environ- } \\
\text { ment Agency warning system, so that improved } \\
\text { warnings for surface flooding can be timely is- } \\
\text { sued. }\end{array}$ \\
\hline
\end{tabular}

- Complementary information displayed on the map:

- Polygon of the Cranbrook catchment: the user can choose whether or not to display a polygon that shows the area comprised by the Cranbrook catchment. This can be done by checking or unchecking the option shown in the top left corner of Fig. 7.

- Polyline indicating the trajectory of the Roding River: same as the polygon of the Cranbrook catchment, the user can choose whether or not to display the trajectory of the Roding River.

- Background map: Google Maps were used as background maps, making it possible to use the tools inherent to these interactive maps (e.g. display of satellite, map and hybrid view, zooming and navigation options).

- Additional visualisation tools provided:

- A special layout was designed that enables simultaneously and adjacently visualising the resulting flood hazard maps for two different alternatives. This enables direct visual comparison of the flood hazard and risk corresponding to two different flood risk management alternatives, thus helping the user in the evaluation and ranking of the alternatives.

- For each of the two adjacent maps, the user can choose (using a drop-down menu) the flood risk management alternative for which to display the flood hazard map.

- For some of the flood risk management alternatives, the user can choose the return period for which to display the flood hazard map.

- As the user explores one of the two displayed maps (by zooming in or out and navigating), the adjacent map is automatically updated to show the same location and zoom. This enables better comparison of the two flood risk management alternatives for which the hazard maps are being displayed.

Figure 7 shows an example of the maps created to illustrate the impact of each flood risk management alternative on the number of properties affected by flooding.

\subsubsection{Step 4 - ranking of alternatives}

The ranking of the FRM alternatives is at the heart of the CME. During the exercise, the alternatives that were identified in step 3 are in a first step ranked individually based on 


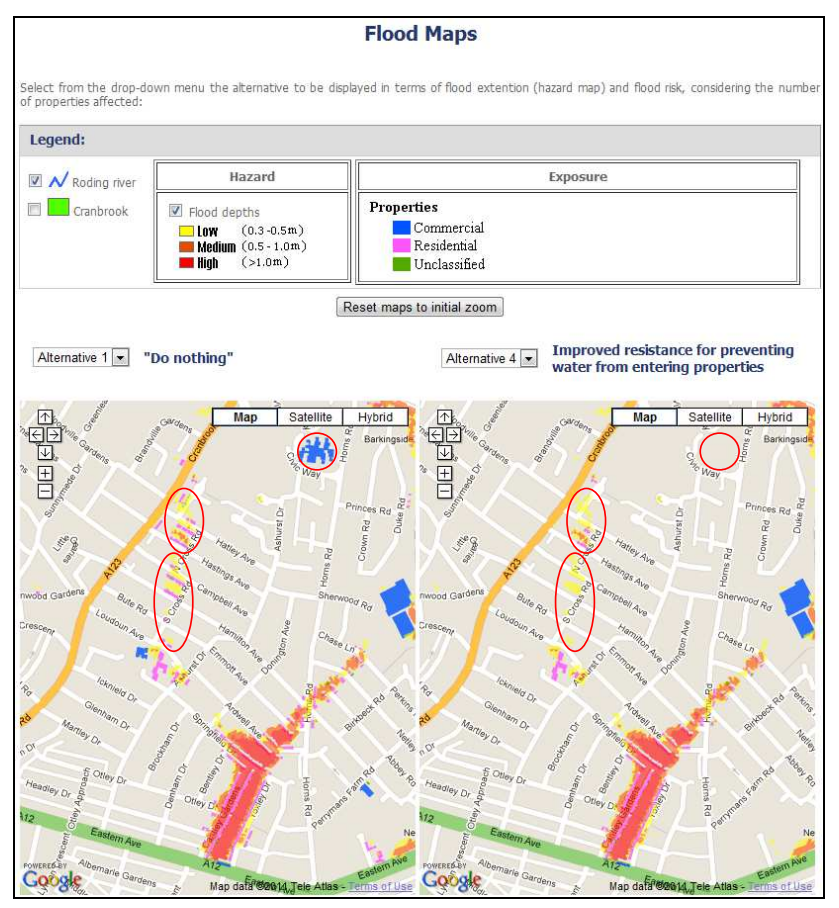

Fig. 7. Example of flood maps created to support assessment of Objective 2 (i.e. ability of the flood risk management alternative to minimise the damage to properties). The red circles point out some of the areas where Alternative 4 (shown in the right window) significantly reduces the number of properties affected by flooding.

the prior-defined objectives for FRM (step 1). Afterwards, a group ranking of alternatives is automatically compiled based on the individual rankings, which is in turn the basis for discussion and negotiation about implementation of FRM measures.

\section{Germany - Alster case study}

The CME in the Alster case was executed with 12 participating stakeholders during a one-day dedicated workshop, and subsequent modifications were carried out online. In this case, the group had a clear preference for the alternative A4, which is comprised of set of preventive measures. The group ranking results are presented in Fig. 9. Again, this is only the result from the group ranking and individual rankings were in fact quite diverse. Given the transparency embedded in this tool, it was possible to analyse attitudes of different types of stakeholders towards different alternatives. This was again possible via the accessibility to the individual profiles of the participants, which contained the same information as in the Cranbrook case, however with one addition: for Alster the stakeholders could propose additional measures/alternatives that should be considered in future FRM analyses.

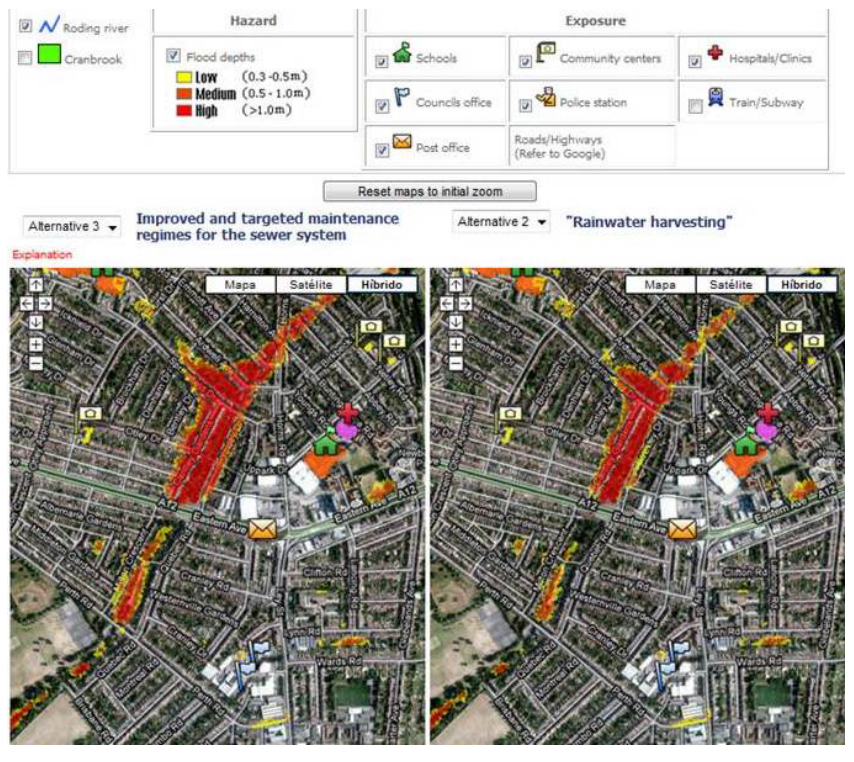

Fig. 8. Interfaces for comparing FRM alternatives.

\section{UK - Cranbrook case study}

The CME in Cranbrook was executed with eight participating stakeholders during a one-day dedicated workshop, and some subsequent modifications were carried out online. The main result was that there was no clear preference by the group about any particular alternatives, and all seemed to be ranked by the group to be quite equal (although there were significant differences in individual rankings). The results are summarised in Fig. 10. The upper part of this Figure indicates the overall alternatives ranking by the group, whereas the lower part represents the same information, but now combined with the individual rankings. In this presentation named "swimming pool of alternatives," more preferred alternatives by the whole group are indicated by darker blue colours and how individuals rank the same alternatives is indicated by individual markers (clustered in yellow when there are more individuals with same position). This visualisation changes as individual participants change their evaluation and ranking, following negotiations. By clicking the markers, evaluation data of any participating stakeholder become visible to all other participants, to ensure maximum transparency. These evaluation data in fact constitute the main part of the individual profile of a given stakeholder. Additional information in this individual profile is textual explanations provided by the stakeholder about the reasoning behind their evaluation and their opinion about which agency is mainly responsible for implementing certain alternative.

After the interaction, CME participants pointed out that an "ideal" solution could be reached by combining alternatives. They also expressed that they found it very interesting to learn about the preferences and ranking of the other participants (as shown in Fig. 10) and that they have learned 

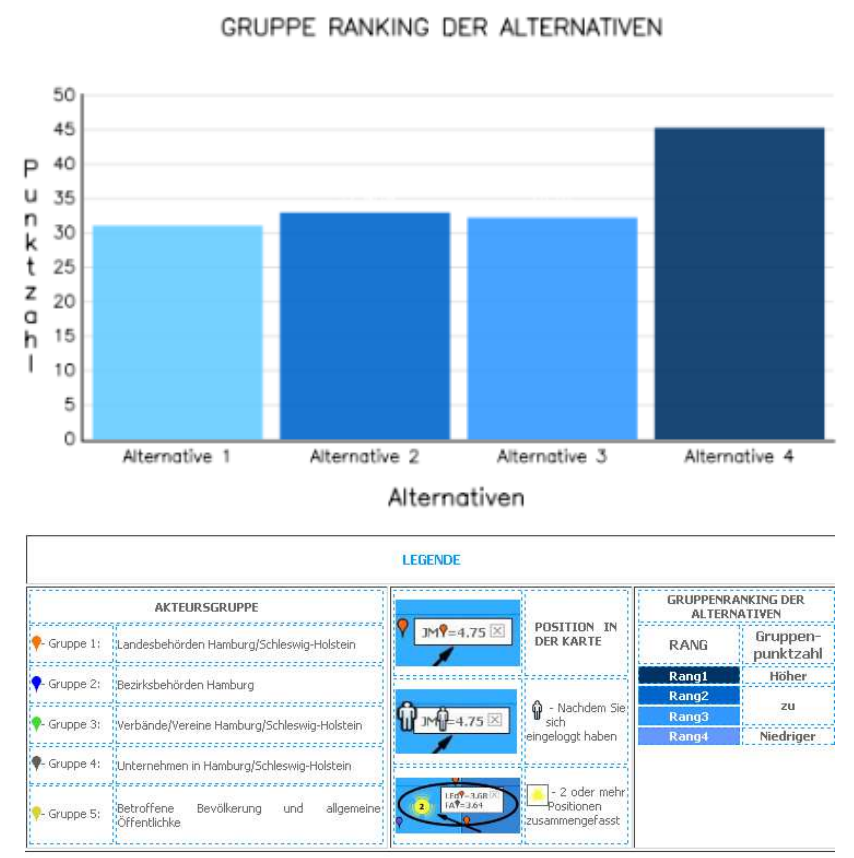

„SWIMMINGPOOL" DER ALTERNATIVEN ZUM HOCHWASSERRISIKOMANAGEMENT IM ALSTERGEBIET

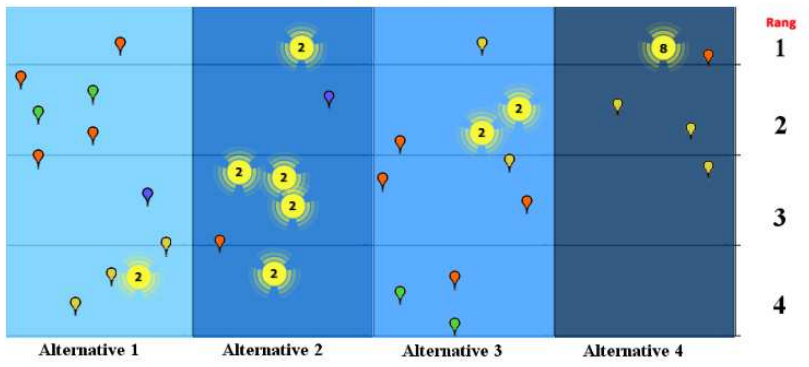

Fig. 9. Group ranking of alternatives for the Alster case. The "swimming pool of alternatives" shows the preference of each CME participant.

about current flood risk in the study area and alternatives for FRM.

\section{Discussion}

The web-based tools and methodologies developed and implemented during the project proved to be useful for promoting interaction between stakeholders, developing shared knowledge, carrying out $\mathrm{CM}$ and achieving social acceptance of new technologies for pluvial flood risk and event management. It was possible to stimulate a social learning process supported by socio-technical instruments. Following Webler et al. (1995) who introduced a set of objectives to be achieved in social learning processes, in Table 5 we summarise how these objectives were achieved by different activities.

Engaging a wide variety of stakeholders in the decisionmaking process for FRM proved to make them more aware of the situation and increased their personal responsibility
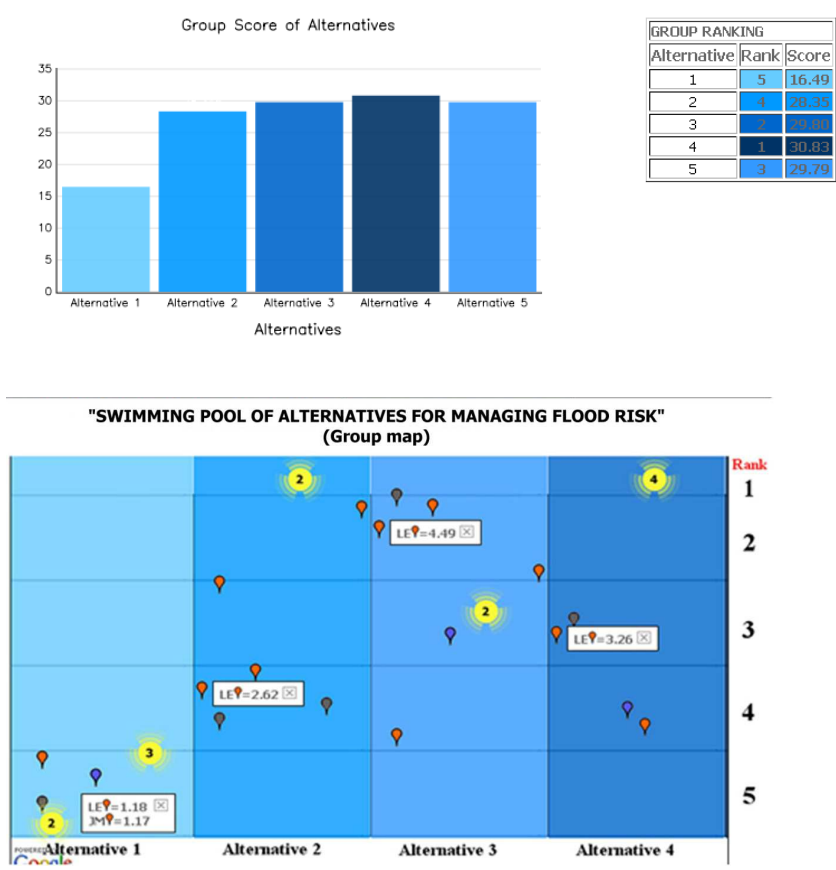

Fig. 10. Group ranking of alternatives in Cranbrook

towards this issue. Furthermore, it enabled assessing their flood risk awareness and their position regarding FRM.

Especially the heterogeneous composition of the group was considered as very fruitful by the stakeholders. The potentially flood affected residents appreciated the exchange with the authorities and that they had the possibility to influence the process and the results of CM process.

Concerning the comparison of alternatives (qualitative and quantitative), the Alster case study dealt with a more general approach; therefore, the CME had more general objectives and alternatives than the Cranbrook catchment. Since the process within the project was of limited time, the results are just an indication about the attitudes of participating stakeholders towards FRM.

The group ranking conducted via the CME indicates the preferences of different stakeholders (objectives, agencies should be responsible for implementation) and points to agreed initial set of measures. However, the results are not conclusive as there were only a limited number of participants within a limited time. We can conclude that more time and effort in identifying objectives/indicators and designing of alternatives would be beneficial.

Given the chosen approach of combining workshops and web-based tools an ideal number of participants would be 20-30 (for effective face-to-face workshops), representing all relevant stakeholders identified during the stakeholder analysis. With a readily available CME tool, such a group would probably be able to arrive at a commonly agreed ranking of alternatives after a period of about $1 \mathrm{yr}$. The long-term goal, however, is that this approach may lead to a kind of 
Table 5. Social learning process supported by activities in DIANE-CM.

\begin{tabular}{ll}
\hline $\begin{array}{l}\text { Objectives for social learning } \\
\text { after Webler et al. (1995) }\end{array}$ & and examples of application in DIANE-CM \\
\hline the state of the problem (information and knowledge); & $\begin{array}{l}\text { Background information on flood risk and regional manage- } \\
\text { ment, current flood risk in Alster and Cranbrook catchment, } \\
\text { feedback from stakeholders and citizens, "hot spot analysis", } \\
\text { CME }\end{array}$ \\
$\begin{array}{ll}\text { Information on and discussion of cause-effect relations, prog- } \\
\text { noses through modelling, scenarios, simulation of alternatives, } \\
\text { (cause-effect relations, predictions); } \\
\text { CME }\end{array}$ & $\begin{array}{l}\text { Discourse in workshops } \\
\text { Discourse via collaborative platform forum, CME }\end{array}$ \\
$\begin{array}{ll}\text { Be asked for interest (interview, workshops) } \\
\text { one's own personal interests (reflection); }\end{array}$ & $\begin{array}{l}\text { Evaluation in the beginning and at the end of the process, CME } \\
\text { CM, workshops, forum, CME, etc. }\end{array}$ \\
$\begin{array}{l}\text { methods, tools, and strategies to communicate well and reach } \\
\text { agreement and practicing holistic or integrative thinking }\end{array}$ & $\begin{array}{l}\text { Defining flood risk and indicators for an assessment, simula- } \\
\text { tion of scenarios and alternatives, including other perspectives, } \\
\text { "getting a bigger picture" }\end{array}$
\end{tabular}

continuous involvement of stakeholders, critically supported by web-based tools adopted and maintained by key FRM authorities. If this is realised, collaborative decisions on new FRM interventions could be reached in shorted periods of time and by involving much larger number of stakeholders.

It needs to be noted that in both case studies the CME exercise did not last sufficiently long for emergence of clear differences in positions (even potential conflicts) that could be resolved by further collaboration and negotiation activities. The CME structure and the supporting visualisation components were developed to provide at least basic support to this process. Additional components specifically designed to analyse individual positions and lead such negotiations would most likely be needed. However, these aspects remain to be tested in further studies.

In spite of the good results achieved with the proposed approach, some barriers for stakeholder involvement remain, and long-term, tailor-made and stronger strategies for stakeholder engagement must be implemented. In Germany, the technical partner LSBG is planning to pursue this approach and also to use the platforms in the future for FRM and public involvement.

It has to be considered that available data and models in an adequate quality are pre-requisites for the CM approach since the simulations of hazards, risk, scenarios and alternatives are key elements. However, in the EU countries where the Flood Directive (2007/60/EC) has to be implemented, this should be the case for areas where a significant flood risk was identified. Here flood hazard maps and flood risk assessment must be conducted. Thus, respective data and models should be available.
We have to state that it was time- and resources-consuming to stimulate (more) online-use and the feedback forum, and the intensity was still low.

Furthermore, the scenarios and uncertainties associated with them need to be better communicated and the interfaces need to be even more diverse for diverse categories of stakeholders (especially true for Alster case study).

Limitation for broader implementation of the project results can be categorised as

- technical restrictions such as the high demand of data required for $\mathrm{CM}$ or the restrictions on data provision in Germany for the drainage system;

- organisational/institutional restrictions like the lack of clear roles and responsibilities for FRM, time limitations for the CME, technophobic persons who were critical to use online tools, or limited willingness for risk communication, different scales of the case study area;

- economic (e.g. lack of appropriate funding and resources) and social restrictions (like motivating heterogeneous stakeholders to get actively involved).

We see three main developments that may help in overcoming these limitations:

1. further training and capacity development of local champions;

2. gradual adoption of the proposed approach by key agencies responsible for FRM as part of their regular activities (instead of project-based engagement with stakeholders); 
3. further development of web applications that allow interactive and collaborative engagement of stakeholders in FRM.

With this in mind, even though the project was finished in September 2011, there are a range of ongoing activities and sustainable implemented results such as

- trained local champions in both case study areas;

- the collaborative platform is planned to be further used in the Alster catchment within the floods directive implementation;

- the e-learning tool and the lessons remain available in the public domain;

- school lessons on FRM are developed, tested and implemented in two schools in Hamburg;

- stakeholders' flood risk awareness and knowledge has risen which will influence the ongoing activities in FRM in both case study areas.

All in all, the CM process and results can be considered as successful and promising approach for enhancing stakeholders' role in FRM in order to increase community resilience ${ }^{5}$.

\section{Conclusions}

The starting point for this study was to investigate how active involvement of stakeholders and social learning processes can be supported via CM. Regarding stakeholder participation, we can draw some general conclusions as follows: Engaging a wide variety of stakeholders in the decision-making process for FRM proved to make them more aware of the situation and increased their knowledge and personal responsibility towards this issue. Furthermore, it enabled assessing their flood risk awareness and their position regarding FRM. We can confirm the findings from recent research that gathering and inclusion of "local" knowledge is essential for participatory governance in FRM. This is particularly true for the successful development and implementation of collaborative modelling methods and tools. The identification and "use" of "local champions" is useful for building up sustainable communication structures and trust through a direct and permanent contact person and moderator for flood risk management. A clear understanding of flood risk is essential as it is the basis for the assessment and ranking of the alternatives for flood risk management. Alternative ways of communicating flood risk were developed with the CM approach and proved to be effective; therefore, their use in future projects can be recommended.

\footnotetext{
${ }^{5}$ For a more detailed discussion and description of further research needs please see Evers et al. (2011).
}

With regard to the $\mathrm{CM}$ approach, we can conclude that this method seems to be a promising way of social learning and active involvement of stakeholders by socio-technical instruments. The web-based tools and methodologies developed and implemented during the project proved to be useful for promoting interaction between stakeholders, developing shared knowledge, carrying out CM and achieving social acceptance of new technologies for pluvial flood risk and event management.

In Germany, the technical partner LSBG is planning to pursue this approach and also to use the platform in the future for FRM and public involvement. In the UK, Imperial College London, together with the Greater London Authority (GLA), is currently implementing this approach in other London Boroughs (starting with the London Borough of Croydon) as part of the development of Community Flood Plans.

The use of web-based tools enables easy access, and clear visualisation of flood risk-related information ensures "transparency" and supports social learning. Face-to-face contact is crucial for carrying out collaborative modelling successfully and could contribute to setting up permanent participation structures for flood risk management. The collaborative modelling approach must be supported by robust flood models, which enable simulating different flood scenarios and flood risk management alternatives in a reliable manner. The use of web-based tools could limit the participation of some groups of stakeholders; some stakeholders, especially older ones, do not normally use computers and are not willing to use the web-based tools developed in the project. Throughout the development of the project, lack of clarity in the role of the different authorities in flood risk management and miscommunication between some of them was identified; communication and coordination between the local and/or regional authorities should be improved. In spite of the good results achieved with the proposed approach, some barriers for stakeholder involvement remain, and long-term, tailor-made and stronger strategies for stakeholder engagement must be implemented.

The collaborative modelling approach proved to be a good way of combining modelling with stakeholder participation for improved flood risk management; however, this approach is highly demanding in terms of data, modelling and time, which makes it unsuitable for short-term management strategies where quick results are required.

\footnotetext{
Acknowledgements. The financial support of the ERANET-CRUE programme is acknowledged. Special appreciation is due to the technical partners such as LSBG in Hamburg, the Redbridge city council and the participating stakeholders who supported this project in the development and running phase. The authors would like to thank the reviewers for the critical comments which helped significantly to improve this paper.
} 
Edited by: A. Thieken

Reviewed by: S. Bender and one anonymous referee

\section{References}

Abbott, M. B.: Stakeholder participation in creating infrastructure, New Civil Engineer, 160, 1, 26-32, Inst. Civil Engineers, London, 2007.

Allitt, R., Blanksby, J., Djordjeviç, S., Maksimoviç, È., and Stewart, D.: Investigations into 1-D-1-D and 1-D-2D urban flood modelling, Paper presented at the WaPUG Autumn Conference, Blackpool, UK, 2009.

De Bruijn, K., Klijn, F., Mens, M., McGahey, C., and Wolfert, H.: Long-term strategies for flood risk management: Scenario definition and strategic alternative design, FLOODsite report T14-0801, 2008.

Centre for Ecology and Hydrology: (formerly the Institute of Hydrology), Flood Estimation Handbook, Wallingford, Oxfordshire, UK, 1999.

Chen, S. and Hwang, C.: Fuzzy Multiple Attribute Decision Making, Lect. Note. Econom. Math. Syst., Springer-Verlag, No. 375, 1992.

Dawson, R. J., Ball, T., Werritty, J., Werritty, A., Hall, J. W., and Roche, N.: Assessing the effectiveness of non-structural flood management measures in the Thames Estuary under conditions of socio-economic and environmental change, Global Environ. Chang., 21, 628-646, 2011.

Djordjeviç, S., Prodanoviç, D., Maksimoviç, È., Ivetic, M., and Saviç, D. A.: SIPSON - Simulation of interaction between pipe flow and surface overland flow in networks, Water Sci. Technol., 52, 275-283, 2005.

EA: What are Areas Susceptible to Surface Water Flooding, Operational instruction 536_10, Issued 16/11/2010, unpublished.

EEA (Ed.): Klimawandel und Anpassung im Wassersektor, available at: http://www.eea.europa.eu/de/publications/briefing 2007_1 (last access: 16 November 2009), 2007.

EEA (Ed.): "Ensuring quality of life in Europe's cities and towns“, available at: http://www.eea.europa.eu/publications/ quality-of-life-in-Europes-cities-and-towns (last access: 16 November 2009), 2009.

Gouldby, B. and Samuels, P.: Language of Risk: Project Definitions, FLOODsite Project, T32-04-01, 2004.

Hisschemöller, M., Tol, R. S. J., and Vellinga, P.: The relevance of participatory approaches in environmental assessment, Integrated Assessment, 2, 57-72, 2001.

Hutter, G., McFadden, L., Penning-Rowsell, E. C., Tapsell, S., and Borga, M.: Strategies for pre-flood risk management - case studies and recommendations, Dresden, FLOODsite Report T13-0701, 2007.

Hwang, C. and Lin, M.: Group Decision Making under Multiple Criteria, Lecture Notes in Economics and Mathematical Systems, Springer-Verlag, 1987.

IPCC: Climate Change: Synthesis Report, IPCC, available at: http:// www.ipcc.ch/pdf/assessment-report/ar4/syr/ar4_syr.pdf (last access: 20 October 2009), 2007.

ISDR: Global assessment report on disaster risk reduction, United Nations, Geneva, Switzerland, 2009.

Jankowski, P.: Collaborative spatial decision making in environmental restoration management: an experimental approach, J.
Hydroinform., 2, 197-206, 2000.

Jankowski, P.: Towards participatory geographic information systems for community-based environmental decision making, J. Environ. Manage., 90, 1966-1971, 2009.

Jonoski, A.: Hydroinformatics as Sociotechnology: Promoting Individual Stakeholder participation by Using Network Distributed Decision Support Systems, Sweets \& Zeitlinger B. V., Lisse, The Netherlands, 2002.

Kilvington, M.: Social learning as a framework for building capacity to work on complex environmental management problems, available at: http://www.landcareresearch.co.nz/ publications/researchpubs/Social_learning_review.pdf (last access: August 2012), 2007.

Makropoulos, C., Katsiri, A., Assimacopoulos, D., and Mimikou, M.: E-learning: roles in distance and traditional postgraduate engineering courses, J. Educat. Inf. Cybernet., 1, 45-50, 2009.

Maksimoviç, È, Prodanoviç, D., Boonya-aroonnet, S., Leitão, J. P., Djordjeviç, S., and Allitt, R.: Overland flow and pathway analysis for modelling of urban pluvial flooding, J. Hydraul. Res., 47, 512-523, 2009.

McGahey, C., Sayers, P., van der Vat, M., Mens, M., and Schanze, J.: An approach to planning for sustainable flood risk management in the long-term (supported by prototype tools), FLOODsite report T18-08-08, 2008.

Mike by DHI: available at: http://www.mikebydhi.com/Products/ WaterResources/MIKE11.aspx, last access: March 2012.

Mostert, E., Pahl-Wostl, C., Rees, Y., Searle, B., Tàbara, D., and Tippett, J.: Social learning in European river-basin management: barriers and fostering mechanisms from 10 river basins, Ecol. Soc., 12, 19, http://www.ecologyandsociety.org/vol12/iss1/ art19/, 2007.

MunichRe: Reasons for the increase in flood losses, available at: http://www.munichre.com/publications/302-04693_en. pdf (last access: 4 December 2009), 2006.

Mustajoki, J., Hämäläinen, R. P., and Marttunen, M. Participatory multi criteria decision analysis with Web-HIPRE: a case of lake regulation policy, Environ. Modell. Softw., 19, 537-547, 2001.

MWH Soft: InfoWorks CS 11.0 help file, Wallingford, UK, 2010.

Pahl-Wostl, C., Craps, M., Dewulf, A., Mostert, E., Tabara, D., and Taillieu, T.: Social learning and water resources management, Ecol. Soc., 12, http://www.ecologyandsociety.org/vol12/ iss2/art5/, 2007.

Pasche, E., Manojlovic, N., Schertzer, D., Deroubaix, J. F., Tchguirinskaia, I., El Tabach, E., Ashley, R., Newman, R., Douglas, I., Lawson, N., and Garvin, S.: The use of non structural measures for reducing the flood risk in small urban catchments, Flood Risk Management: Research and Practice, edited by: Allsop, W., Samuels, P.,Harrop, J., and Huntington S., Taylor \& Francis Group, London, 2009.

Pitt, M.: The Pitt Review: Learning lessons from the 2007 floods, Cabinet Office, available at: http://webarchive.nationalarchives gov.uk/20100807034701/http://archive.cabinetoffice.gov.uk/ pittreview/thepittreview.html (last access: August 2012)), 2008.

Schusler, T. M., Decker, D. J., and Pfeffer, M. J.: Social learning for collaborative natural resource management, Soc. Nat. Resour., 15, 309-326, 2003.

Schwarz, R., Harmeling, S., Kier, G., and Bals, C.: Globaler Klimawandel: Ursachen, Folgen, Handlungsmöglichkeiten, 2. Auflage, German Watch, Berlin, Bonn, 2008. 
Smith, B. and MacGregor, J. T.: What is collaborative learning?, in: Collaborative learning: a sourcebook for higher education, edited by: Goodsell, A. S., Maher, M. R., and Tinto, V., National Center on Postsecondary Teaching, Learning \& Assessment, Syracuse University, USA, 1992.

Soncini-Sessa, R., Castelleti, A., and Weber, E.: Integrated and Participatory Water Resources Management: Theory, Volume 1A, Developments in Integrated Environmental Assessment, Elsevier, 2007a.

Soncini-Sessa, R., Cellina, F., Pianosi, F., and Weber, E. Integrated and Participatory Water Resources Management: Practice, Volume 1B, Developments in Integrated Environmental Assessment, Elsevier, 2007b.

Steinführer, A., De Marchi, B., Kuhlicke, C., Scolobig, A., Tapsell, S., and Tunstall, S.: Recommendations for flood risk management with communities at risk, FLOODsite Report T11-07-14, 2008.

Stern, N.: Stern Review: The Economics of Climate Change, available at: http://www.hm-treasury.gov.uk/stern_review_report.htm (last access: 15 November 2009), 2006.

USACE (United States Army Corps of Engineers): HEC-GeoRAS: GIS tools for support of HEC-RAS using ArcGIS, User's Manual, USACE, Hydrologic Engineering Center, 2009.
USACE (United States Army Corps of Engineers): HEC-RAS, River Analysis System - User's Manual, USACE, Hydrologic Engineering Center, 2010.

Watson, N., Walker, G., Medd, W., Kashefi, E., Tapsell, S., TwiggerRoss, C., and Fernández-Bilbao, A.: Response and resilience in post-flood communities: Lessons from Carlisle, in: Improving response, recovery and resilience, Improving Institutional and Social Responses to Flooding Science Report (SC060019) - Work Package 2, edited by: Fernández-Bilbao, A. and Twigger-Ross, C., EA/Defra Science Report, 2008.

Watson, N., Kashefi, E., Medd, W., Walker, G., Tapsell, S., and Twigger-Ross, C.: Institutional and social responses to flooding from a resilience perspective, Flood Risk Management: Research and Practice, edited by: Samuels, P., Huntington, S., Allsop, W., and Harrop, J., 2009 Taylor \& Francis Group, London, 2009.

Webler, I., Kastenholz, H., and Renn, O.: Public participation in impact assessment: a social learning perspective, Environ. Impact Assess. Rev., 15, 443-464, 1995.

Zhu, X. and Dale, A. P.: JavaAHP: a web-based decision analysis tool for natural resource and environmental management, Environ. Modell. Softw., 16, 251-262, 2001. 